\title{
Buen Vivir (Sumak Kawsay): definiciones, crítica e implicaciones en la planificación del desarrollo en Ecuador
}

\author{
Good Living (Sumak Kawsay): definitions, critique and implications \\ for development planning in Ecuador
}

RESUMEN Con la transición de gobiernos progresistas en la región mientras en Ecuador se mantiene el progresismo, vale recordar algunos hitos del contexto ecuatoriano y la disputa por la acumulación del capital reflejada en el modelo de desarrollo. Este ensayo analiza el Buen Vivir/Sumak Kawsay como alternativa civilizatoria y aborda los planes nacionales de desarrollo. A pesar de que en un inicio se planteó otro modo civilizatorio, con el paso de los años poco se logró concretar de cambio y transformación; una mirada a la década anterior nos deja de saldo un Estado Ecuatoriano moderno, capitalismo con rostro humano. A pesar del vaciamiento del concepto, vale la pena seguir disputando esa dimensión.

PALABRAS-CLAVE Desarrollo económico. Formulación de políticas. Política pública.

ABSTRACT While progressive governments are in transition in the region, in Ecuador the progressive government will continue. It is important to review some key aspects of the Ecuadorean context and its relation with the development model as a reflection of capital accumulation. This essay analyses Good Living/Sumak Kawsay as a civilization alternative and reviews National Development plans. Even though another way of living was proposed, little transformation was actually achieved; looking ten years back, we have a modern Ecuadorean state, a more humane capitalism. Despite Sumak Kawsay currently being empty of content, we suggest it is worthwhile to recover that dimension.

KEYWORDS Economic development. Policy making. Public policy. 


\section{Buen Vivir (Sumak Kawsay): ¿un modo civilizatorio emancipatorio?}

El Buen Vivir es uno de los conceptos desplegados en estos diez años que apuntaló ideológicamente el discurso de cambio que representaba el gobierno progresista en Ecuador. En el marco de la construcción de nuevas constituciones en la zona andina, el Sumak Kawsay/Buen Vivir se plasmó en la Constitución del Ecuador de 2008 y continúa siendo parte significativa de los debates a nivel nacional, regional y mundial.

Con la fuerza y plataforma importante de los movimientos sociales ecuatorianos históricos y en el contexto latinoamericano con el gobierno de Chávez ya en el poder, Ecuador logra afianzar una propuesta alternativa que intenta consolidar el sueño de justicia social, equidad y 'otro mundo posible' de varias décadas y que se refleja en la mencionada Nueva Constitución 2008 y en esa noción del Buen Vivir.

Con el nuevo panorama de transición de gobiernos progresistas en la región mientras en Ecuador todavía se mantiene el progresismo, vale la pena recordar algunos hitos del contexto ecuatoriano y su relación con la disputa por la acumulación de capital propiciada por el modelo de desarrollo. En este ensayo se analiza el Buen Vivir/Sumak Kawsay propuesto como modo civilizatorio para el país y se ejemplifica la contraposición de ambas visiones en el campo de la salud ancestral e indígena vs. desarrollista representada por el complejo biomédico hegemónico industrial. Finalmente se abordan los planes nacionales de desarrollo que dan cuenta de la variación del énfasis en varios aspectos a lo largo de la década: soberanía y tratados de libre comercio, reforma agraria, cambio de matriz productiva; todas ellas dimensiones importantes para el cumplimiento efectivo del derecho a la salud, que es un derecho en interdependencia con otros derechos.

\section{Contexto}

Desde los años setentas el Ecuador ha sido un país petrolero ligado a la "paradoja de la abundancia", fenómeno que describe la incongruencia de que las naciones ricas en recursos naturales, y cuyas economías se basan en la extracción-exportación de dichos recursos, están "destinadas a la pobreza" (ACOSTA, 2011, P. 83). Este destino es la herencia resultante de alianzas de élites del Norte y transnacionales con las burguesías locales del Sur Global tanto productivistas como rentistas y agravada por la superexplotación descripta por Marini, en una continuidad de la colonia a la dependencia (RUIZ, 2013).

Para fines de los años '80, en Latinoamérica se hablaba de la 'década perdida' y en los años '90 se aplicaban reformas neoliberales en todos los países del continente. En el caso del sector de la salud en Ecuador se promovían Fasbase (Fortalecimiento y Ampliación de los Servicios Básicos de Salud) y Modersa (Proyecto de Modernización de los Servicios de Salud) que - bajo el auspicio del Banco Interamericano de Desarrollo - pretendían privatizar los servicios de salud públicos bajo consignas de 'eficiencia, efectividad, calidad y equidad'. En la década de los años '90 y con varios movimientos y organizaciones sociales sólidas, como el Seguro Social Campesino y el Movimiento Indígena-con la Confederación de Nacionalidades Indígenas del Ecuador (Conaie) o la Federación Nacional de Organizaciones Campesinas, Indígenas y Negras (Fenocin), entre otras, se logra poner freno a la firma del Tratado de Libre Comercio con EEUU y a la privatización de la Seguridad Social.

A fines de la misma década e inicios del nuevo milenio se derrocan los gobiernos de Mahuad, Bucaram y Gutiérrez por su imposición de medidas al servicio del capital como la crisis bancaria del 2000, que congela los ahorros de los ecuatorianos y ecuatorianas para salvar a la banca privada o la instalación de la base militar norteamericana en Manta como punto de control geopolítico.

En Ecuador se logra una movilización 
social substancial y en el 2006 varias organizaciones históricas como el movimiento de mujeres, los campesinos, los indígenas, y colectivos académicos que cuestionaban el pago ilegítimo de la deuda externa, entre otras, incluyen sus agendas en el programa de Alianza País y modelan, en sus inicios, el proyecto político en torno a otra propuesta, una alternativa al desarrollo.

El Sumak Kawsay es una propuesta que pretende centrar la sociedad en el sujeto, un intento de reconstrucción del vínculo sujeto-objeto, una creación de comunidad inspirada desde el ayullu y la propuesta del movimiento indígena ecuatoriano para unos (SIMBAÑA, 2011) mientras que para otros es el resultante del debate de intelectuales mestizos que luego se incorpora a las demandas del movimiento indígena (ALTMAN, 2013).

\section{Modelo de desarrollo: ¿qué es desarrollo?}

El desarrollo es un concepto relacionado a la calidad de vida, bienestar, salud y felicidad que se lograría si se siguen ciertas recetas ligadas al imaginario que en la sociedad occidental de consumo se tiene de un estilo de vida apropiado. El Grupo Permanente de Trabajo sobre Alternativas al desarrollo, citando a Foucault y a Arturo Escobar, define al desarrollo como:

Un dispositivo de poder que reorganizó al mundo, relegitimando la división internacional del trabajo en el contexto capitalista, mediante un enorme conjunto de discursos y prácticas. El desarrollo se transformó en objetivo de las políticas públicas, se destinaron presupuestos y se crearon múltiples instituciones encargadas de impulsar al desarrollo, a escala local, nacional e internacional [.... En los países del Norte, lo que antes eran políticas económicas frente a las colonias se resignificó en términos de 'cooperación internacional' al desarrollo. (LANG; MOKRANI, 2011, P. 13).

Así como existen formas de vida a imitar en el Norte - formas de vida que se alcanzarían con el 'desarrollo'- con la categoría de subdesarrollo se desvalorizan los modos de vida, relacionamientos sociales y saberes existentes en el Sur. De esta forma con el desarrollo, el crecimiento económico y el sueño de progreso que este paradigma implica y que se despliega con el discurso de las agencias internacionales como Naciones Unidas, la cooperación internacional y algunas políticas públicas globales como los Objetivos de Desarrollo del Milenio, se perpetúa visiones economicistas sin tener en cuenta los sacrificios que dicho crecimiento económico impone en la periferia; así por ejemplo el desastre ambiental en Marianas y la pérdida de vidas en deslave tóxico en Brasil, cientos de campesinos y campesinas desplazados de sus tierras por el agronegocio a nivel global, migraciones masivas desde Medio Oriente a Europa por las guerras desencadenadas por la posesión de petróleo, entre otras; todas ellas afectaciones directas al ejercicio efectivo del derecho a la salud.

En este escenario, los países subdesarrollados - Latinoamérica inclusive - debían seguir los pasos de aquellos industrializados. El tema central era el crecimiento económico y no las formas de distribución de esa riqueza, de hecho el bienestar de la población queda subordinado al crecimiento y progreso, pues la desigualdad y la pobreza se resolvían en términos económicos. He ahí la importancia de medir el Producto Interno Bruto o el Índice de Desarrollo Humano.

En respuesta a políticas neoliberales, como la privatización de servicios de salud, los programas de salud focalizados para pobres o los tratados de libre comercio y a la presión por un desarrollo que implicaba la integración a la sociedad de consumo, se plantean desde el Sur otras alternativas.

Entre esas alternativas está el Buen Vivir como una crítica a la modernidad o al "maldesarrollo que conduce al malvivir" según Tortosa (APUD HOUTART, 2011, P. 63). En ese sentido, la crisis del modelo de desarrollo dominante que entiende la naturaleza como subordinada 
al hombre y que impone una visión utilitarista, fragmentada de aquella en una serie de elementos - recursos naturales - (HOUTART, 2011), es cuestionada con la idea del Sumak Kawsay.

\section{Buen Vivir / Sumak Kawsay: definiciones}

\author{
Padre Fuego: Ni más ni menos no somos porque \\ nosotros mismo somos fuego. Yakumama: \\ Ni más ni menos no somos porque nosotros \\ mismo somos agua. Padre Viento: Ni más ni \\ menos no somos porque nosotros mismo somos \\ aire. Pachamamita: ni más ni menos no somos \\ porque nosotros mismos somos tierra. \\ Carmen Cumba, Oración ceremonial en \\ Jambi Warmi Kuna
}

Con una crítica al modo de vida occidental, Choquehuanca - ex canciller boliviano - describe lo que implica el desarrollo para los y las indígenas. Se parte del supuesto de que éste traería beneficios de la modernidad, un vivir mejor, a través de la integración de los pueblos indígenas al mercado y de su fuerza laboral. Con ello se logra apartarlos de sus usos y costumbres ancestrales - valor de uso - para convertir en valor de cambio actividades como el turismo comunitario; obligando a la renuncia de formas de subsistencia milenarias y con ella, a la autodeterminación de sus territorios, lo que más tarde permitiría la explotación minera o petrolera (CHOQUEHUANCA, 2010).

En el campo de la salud estos argumentos cobran sentido en el caso de México, por ejemplo, en el que la diabetes propiciada por el consumo de bebidas azucaradas y comida chatarra que produjo medio millón de muertes en los últimos seis años, no impactaba a la población indígena debido a su alimentación tradicional y ligada al agro, en síntesis, un modo civilizatorio distinto. Sin embargo desde el 2010 - con la expansión de la industria de bebidas azucaradas - inicia la dotación de refrigeradoras en las comunidades y se favorece la transferencia de ayuda pública para consumo de estos alimentos. Hoy pueblos como los mazahuas han abandonado su alimentación milenaria y presentan niveles altos de hiperglucemia, así como la doble carga de desnutrición y sobrepeso que se acompaña de una ausencia de servicios de salud (MARCIAL, 2016); demostrando que la preservación de la alimentación tradicional ligada a la soberanía alimentaria que se ejerce en el territorio construye salud.

En este contexto Luis Macas, dirigente histórico de la Conaie, define el Sumak Kawsay, Buen Vivir o Vida en Plenitud como:

la vida en excelencia material y espiritual. La magnificencia y lo sublime se expresa en la armonía, en el equilibrio interno y externo de una comunidad. Aquí la perspectiva estratégica de la comunidad en armonía es alcanzar lo superior [...]. La convivencia es posible en tanto existan los onsensos y la voluntad y las condiciones para lograr la armonía en la comunidad, obviamente la comunidad y la naturaleza. Estas formas de relaciones determinan las formas y los sistemas de vida en los seres humanos. Es decir que somos colectivos. Todos los pueblos originarios, incluso en el occidente, nacieron así. Luego nos individualizan, nos ciudadanizan. (MACAS, 2010, P. 14).

Los siguientes elementos básicos diferencian al Sumak Kawsay del capitalismo, considerando que el Buen Vivir no equivale a Estado de Bienestar: 1) el sujeto es colectivo, 2) existe complementariedad; aprovechamiento de recursos naturales y trabajo comunitario o colectivo 3) hay una valoración de las relaciones comunitarias en el uso de los bienes, 4) se promueve una abstención de la acumulación y la ritualización/redistribución del excedente y 5) se fundamenta en la armonización con el entorno y la Naturaleza (MALDONADO, 2009).

Los contrastes del capitalismo y de los modos de vida de los pueblos y nacionalidades ancestrales que defienden y dan el significado al Sumak Kawsay se pueden visibilizar mejor en el siguiente cuadro: 
Cuadro 1. Comparación concepción del capitalismo vs concepción del Sumak Kawsay

\begin{tabular}{|c|c|}
\hline Capitalismo & Sumak Kawsay \\
\hline Propiedad privada - capital & Propiedad colectiva y familiar \\
\hline Ser humano egoísta - Sujeto económico individual & Sujeto económico colectivo \\
\hline Busca rentabilidad económica individual & Busca bienestar de la comunidad \\
\hline Acumulación & $\begin{array}{l}\text { Predominio de instituciones de reciprocidad social (redistribu- } \\
\text { ción) }\end{array}$ \\
\hline Control del mercado & Mercado espacio de intercambio excedentes y complementación \\
\hline \multicolumn{2}{|l|}{ Obsesión por el Crecimiento Económico } \\
\hline \multicolumn{2}{|l|}{ Predominio de las Empresas Privadas } \\
\hline Depredación de recursos naturales & $\begin{array}{l}\text { El ser humano es parte de la naturaleza (reciprocidad sacraliza- } \\
\text { da) }\end{array}$ \\
\hline $\begin{array}{l}\text { Producción orientada a satisfacer necesidades } \\
\text { creadas desde las empresas }\end{array}$ & $\begin{array}{l}\text { Satisfacción de necesidades y re-establecimiento de alianzas } \\
\text { para garantizar acceso a recursos }\end{array}$ \\
\hline Reglas del mercado, oferta y demanda & \\
\hline
\end{tabular}

Fuente: Maldonado (2009).

Como se puede observar, en el Sumak Kawsay se considera a la naturaleza como un ser vivo y como objeto de cuidado o sujeto de derechos. Se puede deducir que la salud en ambos esquemas es distinta desde su concepción original: la una es producto de la acción individual, el sometimiento a un complejo biomédico industrial que patologiza procesos fisiológicos como el parto o nos somete a un sistema alimentario dependiente de las grandes empresas; la otra está ligada al ser humano en tanto su relación con el entorno y la comunidad, con el territorio y su conexión sacralizada con este, con la soberanía alimentaria como expresión de la salud: la salud colectiva.

El Sumak Kawsay como ética que ordena la vida de la comunidad, se hace visible en las familias y comunidades o ayllus en Ecuador y esa ética resiste el proceso de colonización. Durante la década de los 90, con la lucha contra los tratados de libre comercio y el modelo económico que proponía tecnología y modernización como puntales para el crecimiento, el movimiento indígena ecuatoriano impulsa la defensa de la soberanía alimentaria, la reforma agraria y posiciona la propuesta de un Estado Plurinacional
(SIMBAÑA 2011). Lo comunitario es el corazón de la propuesta plurinacional y del Sumak Kawsay y la comuna es el espacio de reproducción histórica e ideológica de los pueblos indios en sus ámbitos material, cultural y espiritual. Allí se recrean los principios de reciprocidad, propiedad colectiva, relación y convivencia con la naturaleza, responsabilidad social y consensos. La comuna es entonces, un modelo concreto y en contradicción con el neoliberalismo y el desarro1lo/progreso que este implica (SIMBAÑA, 2011).

Así como en Ecuador se definió un Sumak Kawsay (en lengua kichwa), en Bolivia se defendía el Suma Qamaña (en aymara) o el "convivir bien" y no vivir mejor que los otros, incorporando la dimensión material pero también la espiritual (HOUTART, 2011, P. 70). Por ello, es imposible separar la idea de equidad y justicia social de la relación con la naturaleza pues

no se puede pensar en sostener, o lo que es peor, expandir la explotación petrolera, minera y de otros bienes naturales bajo la promesa de una redistribución y una mayor participación estatal, sin seguir debilitando la economía social de los pueblos (SIMBAÑA, 2011, P. 223) [y por consiguiente, su salud]. 
Dicho de otro modo y con una perspectiva ecosocialista: las heridas de actividades productivas como la explotación petrolera en territorio de pueblos no contactados, dejan tras de sí desequilibrios socio ambientales nefastos en lo que Veraza califica como la mutación de fuerzas productivas en fuerzas destructivas que despliegan la esencia del modelo de producción capitalista que es a la vez progreso y decadencia (RUIZ, 2013).

Proyectos como el ecosocialismo que se relacionan con el Buen Vivir, tienen según Ruiz (2013), un doble reto: luchar por una distribución equitativa de las fuentes de riqueza o fuerzas productivas como la tierra, el agua, la ciencia, la técnica, el conjunto de saberes que garantiza la reproducción de la vida como salud, educación, entre otros

y por la transformación radical de aquellas fuerzas que se han vuelto destructivas, aunque en el presente sean ellas mismas fuentes de producción de riqueza. (RUIZ, 2013, P. 4).

En el escenario ecuatoriano se plantean las preguntas: ¿̨cuántos pozos petroleros en territorios ancestrales, cuyos derrames ocasionan cáncer en los habitantes de la zona, deben admitirse para que los recursos fiscales obtenidos de esa actividad extractiva se destinen a la construcción de hospitales con tecnología de punta? ¿Cuántas concesiones mineras?

A pesar de que teóricos indígenas como Choquehuanca diferencian el Buen Vivir tanto del socialismo como del capitalismo, Houtart (2011) demuestra que no existe una discrepancia entre Buen Vivir y socialismo al rescatar la crítica de Marx respecto del capitalismo como la causa de la separación entre hombre y naturaleza y de la constante relación del hombre con aquella, que es la relación consigo mismo.

Como el Buen Vivir no implica únicamente la satisfacción de necesidades, el acceso a bienes y servicios básicos o la acumulación de bienes, los indicadores para comparar unas naciones con otras como el Producto Interno Bruto o el Índice de Desarrollo Humano, los Objetivos del Milenio u otras medidas globales, no logran reflejar el estado del vivir bien/conexión con la naturaleza, dimensión material/espiritual que el Buen Vivir encierra. O cómo resume Altman (2013, P. 292) respecto de la conexión espiritual entre pueblo, territorio y metafísica que es una relación compleja: el territorio es

parte integral de la identidad del pueblo y por tanto no puede ser separado del mismo, por lo que la relación entre pueblo y territorio es muy diferente de la que prevalece entre la población mestiza.

\section{Críticas al Buen Vivir: el caso del sector salud y la potenciación del modelo biomédico hegemónico}

Críticas al Buen Vivir en tanto discurso implementado desde el Estado, existen y son contundentes. Críticas como la de Viola, apelan a que el Buen Vivir resulta de una idealización de la cosmovisión y los valores de las culturas andinas y con ello un invento que se presenta como alternativa al desarrollismo pero que solo permite la continuidad entre el desarrollismo y el invento (VIOLA APUD DOMINGUEZ; CARIA, 2014, P. 35).

De este modo, según Domínguez y Caria (2014, P. 27), el Buen Vivir se ha convertido en un "aparato ideológico del Estado", funcional a objetivos desarrollistas normales como: el aumento del Producto Interno Bruto per cápita con reducción de la pobreza y de la desigualdad. Este enfoque en inequidades sociales en el marco de un capitalismo con rostro humano, está lejos de la vida en plenitud y cercano al consenso de Washington o nuevo desarrollismo.

Para ello basta un ejemplo: la redistribución de tierray agua en el Ecuador durante el período de la Constitución del Buen Vivir ha sido nula con $5 \%$ de propietarios que concentran el $52 \%$ de las tierras agrícolas mientras que el $60 \%$ de pequeños productores son propietarios solo del 
6.4\% (SENPLADES, 2013 APUD DOMINGUEZ; CARIA, 2014, P. 28). Es así que el Buen Vivir pasa a ser un discurso ideológico que enmascara la realidad y termina como una mentira que se propaga como verdad (DOMINGUEZ; CARIA, 2014).

$\mathrm{Si}$ Ecuador ha mejorado las condiciones socio-económicas del país en la última década, ello se debe a las transferencias condicionadas - Bono de Desarrollo Humano - y a políticas sociales de protección social directa a las familias más que a un cambio de modelo económico que apuntale la transición hacia otro paradigma.

Enelsector salud, los diez años de Revolución Ciudadana se califican de exitosos así: construcción de 13 hospitales y ocho adicionales en proceso de construcción, 61 nuevos centros de salud entre centros grandes y pequeños y 34 centros de salud adicionales en construcción. Se logra la certificación internacional de 39 hospitales públicos mientras que con respecto a la vacunación, se pasa de 11 a 20 vacunas específicas administradas por el sistema público con una inversión de 60 millones de dólares. Se triplica la cantidad de profesionales en la salud pasando de 9 por cada mil habitantes a 20 por cada mil habitantes, así como se incrementa el número de horas de trabajo de dichos profesionales de 4 a 8 horas. Para el 2016 solamente se realizaron 41 millones de atenciones de salud. La inversión total en 10 años de gobierno es de 16.188 millones de dólares (ECUADOR..., 2017).

Así mismo, en seguridad social se detallan los logros respecto del incremento del número de médicos - 5800 en 2006 a 17000 en 2016 -, el incremento en el número de unidades médicas a nivel nacional con un total de 97 unidades médicas y 659 dispensarios de salud. Para el Seguro General Obligatorio se cuenta con 3'415.015 afiliados - que si se incluyen los beneficiarios del seguro general de salud individual y familiar llegarían a los 9.187.917; mientras que 1.277.983 afiliados pertenecen al Seguro Social Campesino. Adicionalmente se coloca como logro el incremento de la jubilación de quienes aportaron más de 40 años en 70\% a lo largo de siete años (ECUADOR..., 2017).

Sin embargo, todos los logros descriptos arriba narran únicamente la consolidación de un complejo biomédico hegemónico en salud. Esto implica que aunque desde el 2006 se haya invertido y modernizado o ampliado la cobertura de servicios de salud curativos:

El impacto favorable de esta política se ve enmascarado por la proliferación de procesos malsanos (supeditados a las condiciones impuestas por el productivismo en ambientes deteriorados física o culturalmente), que se multiplican en los escenarios donde la gente vive, trabaja o se recrea y cuyo efecto va contracorriente respecto a la curación que ofrecen los servicios. (BREILH, 2014, P. 4).

De hecho, a pesar del incremento en la inversión en el sector salud con la 'revolución ciudadana', la mortalidad materna, como ejemplo paradigmático en el impacto en salud pública, no se redujo. Según Noboa (2015), la mortalidad materna no ha disminuido significativamente en estos 24 años, de cifras que fluctuaron entre 84,6 y 96,1 x 1000 nacidos vivos (nv) en los primeros años de la década de 1990, la razón de mortalidad materna ha descendido a cifras que fluctúan entre 45,7 y 70,4 x 1000 nv en los 4 últimos años de los que se dispone datos 2010-2013. Varios estudios recientes demuestran que la inversión en salud en los diez años de la revolución ciudadana propició la acumulación de capital en la industria de insumos, farmacéuticas, aseguradoras privadas (DÁVALOS, 2016; ITURRALDE, 2014); impulsó el desmantelamiento de la Seguridad Social con la transferencia de fondos públicos a clínicas privadas (DÁvALOS, 2016) y no logró que los hogares ecuatorianos gasten menos en salud: las familias continuaban asumiendo los principales desembolsos en salud con un $45 \%$ del total del gasto como gasto de bolsillo mientras que un $29 \%$ pertenece al gobierno y solo un $23 \%$ a la seguridad social (ITURRALDE, 2014).

De esta manera, los programas de inclusión social llevados a cabo desde la Constitución del 2008, fueron un intento de modernización 
del Estado con redistribución, siguiendo la hipótesis de Breilh (2014) sobre la Transición al Neo-productivismo con Gobernanza. Ya para el 2014 se pueden enmarcar a esos programas sociales en una inclusión social limitada necesaria para lograr gobernanza en el país sin lograr un verdadero cambio del modelo de acumulación. Se cambia la política neoliberal de privatización en el sector salud de los ochentas y noventas por

una renegociación mínima de las remuneraciones, el dispendio inorgánico de subsidios con programas tibiamente redistributivos y una modernización de la institucionalidad pública. (BREILH, 2014, P. 7).

Es más, cuando a inicios del 2015 se verificó que la reducción en mortalidad materna era otro tema rezagado en la política de salud del gobierno progresista de Alianza País, se ofrecieron medidas de corrección con disminución de los sueldos de altos funcionarios de gobierno para invertir en la contratación de 1000 médicos alópatas adicionales (ECUADOR, 2015) sin reparar en la Atención Primaria de Salud como estrategia ni en el rol de parteras, promotores de salud, agentes tradicionales y su contacto cercano con las comunidades rurales e indígenas de las que son parte y que usualmente cuentan con menor cobertura de atención materno infantil. De esta manera se potencia el modelo de acumulación bajo el complejo biomédico industrial.

Se concreta en salud un modelo de salud moderno, curativo, dependiente del extractivismo y los recursos económicos que este genera y que se invertirán en una especie de saco sin fondo, dado que continuaremos con la afectación a la salud y a los modos de vida de las víctimas colaterales del ideal de progreso. Mientras tanto, la salud concebida como relación con el territorio, la ritualidad y sacralización de la naturaleza, la conservación de la semilla nativa y de los saberes ancestrales en alimentación ligados a la soberanía alimentaria, la atención del parto como proceso fisiológico y otras prácticas que promueven los agentes tradicionales de salud como parteras y sus asociacionesrelacionadas con la concepción de Sumak Kawsay evidenciada en la segunda columna del cuadro 1, se vuelve aún más marginal.

\section{Planes Nacionales de Desarrollo y Cambio de Matriz Productiva: el vaciamiento del concepto de Buen Vivir}

$\mathrm{Al}$ inicio del período de gobierno de Alianza País se contó con un Plan Nacional de Desarrollo 2007-2010 que detalló el 'cambio de modo de Estado', de forma que este recupere sus bases de gestión, planificación, regulación y redistribución. Su objetivo era fomentar la igualdad y la cohesión social (KING, 2014).

Ya para el 2009 se lanza el primer Plan Nacional del Buen Vivir (PNBV 20092013) en el que René Ramírez - Secretario Nacional de Planificación - define el Buen Vivir así:

La satisfacción de las necesidades, la consecución de una calidad de vida y muerte digna, el amar y ser amado, el florecimiento saludable de todos y todas, en paz y armonía con la naturaleza y la prolongación indefinida de las culturas humanas. El Buen Vivir supone tener tiempo libre para la contemplación y la emancipación, y que las libertades, oportunidades, capacidades y potencialidades reales de los individuos se amplíen y florezcan de modo que permitan lograr simultáneamente aquello que la sociedad, los territorios, las diversas identidades colectivas y cada uno - visto como un ser humano universal y particular a la vez - valora como objetivo de vida deseable (tanto material como subjetivamente y sin producir ningún tipo de dominación a un otro). (ECUADOR, 2009, P. 6). 
De esta forma, a pesar de que el PNBV 2009 - 2013 cuestiona el Consenso de Washington abiertamente e intenta en su narrativa poner en el centro del debate a la acumulación, producción/reproducción de capital, con retórica de una estrategia económica incluyente, sostenible y democrática que lleve a la redistribución (2009), con el concepto de Buen Vivir de Ramírez, que es todo y nada a la vez, evadiendo la relación con el territorio, podemos asumir que fue un discurso producto de un ejercicio teórico burocrático más que una visión con potencialidades para la transformación de la realidad.

En concreto, en el PNBV 2009-2013 se equipara el Buen Vivir con el 'desarrollo humano sustentable' y en torno a la noción de un cambio económico equitativo, se plantea el desarrollo con base en el turismo comunitario, la redistribución de tierras y aguas, la economía del conocimiento, el sector de la construcción, del software-hardware, de la industria de alimentos, entre otros; así como en torno a la sustitución selectiva de importaciones y diversificación de exportaciones. Sin embargo, el turismo no contó con políticas o inversión apropiada como para convertirse en un eje del cambio económico y la redistribución de tierras y aguas continuó siendo una deuda; tampoco la sustitución selectiva de importaciones y diversificación de exportaciones se concretaron (OSPINA, 2013). Es más, en todas las nociones del Buen Vivir del gobierno ecuatoriano, aun cuando el enfoque sea el de equidad, se vacía del contenido territorial/defensa de los territorios con el trasfondo metafísico que el Sumak Kawsay impulsado por el movimiento indígena planteaba, así:

los intelectuales no-indígenas se refieren sobre todo a la idea de una relación armónica entre individuo, sociedad y naturaleza, mientras el movimiento indígena expande el concepto al comprender en él al territorio. (ALTMAN, 2013, P. 296).

Para el siguiente período se cuentan nuevos ajustes así, aunque el Plan Nacional del Buen Vivir 2013- 2017 señala la importancia de las pautas distributivas y redistributivas y no simplemente el crecimiento económico como fundamento del Buen Vivir en la narrativa, es claro que lo que se fortalece es el cambio de matriz productiva. Con la salida de Lenin Moreno y el ingreso de Jorge Glas a la Vicepresidencia de la República en el 2013, esta instancia de gobierno asume un rol protagónico en el cambio productivo y el control de sectores estratégicos. Esta nueva tarea que incluye una Secretaría Técnica de la Matriz Productiva, reemplaza al enfoque de 'inclusión social' de la Vicepresidencia hasta entonces y prioriza 'megainversiones y megaproyectos' por sobre el componente social. Mientras tanto, la Secretaría Nacional de Planificación y Desarrollo (Senplades) se encarga - a través de la Secretaría Técnica para la Erradicación de la Pobreza - de lo social, con un rol menor (KING, 2014).

Para el PNBV 2013-2017 se coloca énfasis en el cambio de matriz productiva y dentro de esta en el cambio de matriz energética; igualmente, se coloca a la minería y a la industrialización de productos mineros como puntales de desarrollo, junto con la economía del conocimiento y la inversión masiva en el proyecto emblemático de la Universidad del Conocimiento Yachay. Con la preponderancia de lo descripto es claro que se priorizó la infraestructura (OSPINA, 2013) y con ello se potencia el mito del progreso y el modelo extractivista, con las afectaciones a la salud evidentes en ese tipo de 'desarrollo' que separa al sujeto del objeto/ hombre de la naturaleza, ahonda la herida en el territorio y la crisis climática global.

En el período del 2013 hasta la fecha, la propuesta del Yasuní ITT - mantener el petróleo bajo tierra con apoyo financiero de la comunidad internacional - que era el ejemplo de promesa de un cambio, una alternativa al desarrollo, hacia la construcción del Sumak Kawsay - se deja de lado. Ya para mediados del 2013 se inicia más bien la firma del Tratado de Libre Comercio con la Unión 
Europea y con ello, un marcado abismo entre lo alternativo - Sumak Kawsay - y el concepto vaciado de contenido que usó el gobierno ecuatoriano para continuar con el modelo primario exportador.

El cambio de matriz productiva es un claro ejemplo de la planificación para el mismo modelo de desarrollo y el vaciamiento del concepto del Sumak Kawsay. Según Villavicencio (2016) con el discurso de la transformación permanente que está a punto de llegar, con discursos grandilocuentes que no terminan de delimitar cuál es el cambio del modelo de acumulación, lo que se tiene en concreto es una planificación para treinta años dependiente de obras gigantes de infraestructura y consolidación de siderurgia, cobre, hidroeléctricas; es decir, sin transformación.

El cambio de modelo de acumulación se basaba en la transición de una economía primario - exportadora a una economía del conocimiento y así se plantearon grandes metas como:

i) aumentar la participación de la industria en la composición del producto nacional, ii) diversificación 'inteligente' de las exportaciones e incorporación de mayor valor agregado a través de productos manufacturados, iii) dinamización del mercado interno y substitución selectiva de importaciones, iv) generación de empleo de calidad y v) desconcentración de la riqueza. (VILLAVICENCIO, 2016, N. P.).

Sin embargo, solo en la política de desarrollo selectivo de la industria se verificó que para el 2013 la participación de la industria manufacturera decreció a $12.4 \%$ comparado con el $13.7 \%$ del 2007 , en la cifra más baja de los últimos treinta años (VILLAVICENCIO, 2016). Así mismo, para el 2013 el déficit de la balanza comercial no petrolera por incremento de importaciones superó los 9.000 millones de dólares, razón por la que se creó un sistema de salvaguardias mientras que si nos referimos a la democratización de los medios de producción: en 2003 los ingresos de las 400 empresas más grandes que operaban en el Ecuador representaban alrededor del 50\% del PIB y en 2014 sus ingresos ya habían alcanzado el equivalente al 58\%. (VILLAVICENCIO, 2016, N. P.).

Finalmente, el cambio de matriz productiva se fundamenta en la hidroelectricidad y en la explotación de recursos naturales como cobre y hierro evidenciando el vaciamiento del concepto del Sumak Kawsay impulsado por el movimiento indígena al escindir de aquel el territorio; es entonces el Buen Vivir

puro capitalismo neoliberal: la tierra, el territorio como objetos desprovistos de todo valor intrínseco, de toda relación social y toda significación simbólica se convierten en piezas sobre los cuales se ejerce la violencia de la acumulación capitalista. (VILLAVICENCIO, 2016, N. P.).

\section{Conclusiones}

A pesar de que el Sumak Kawsay (Buen Vivir) fue apoyado a inicios del período por el gobierno de Alianza País y en la Asamblea Constituyente, con una Constitución en varios aspectos progresista, con el paso de los años poco se logró concretar de cambio y transformación. Hoy una mirada a la década anterior nos deja de saldo un Estado Ecuatoriano moderno, con énfasis en la eficiencia y meritocracia; un capitalismo con rostro humano.

En una apreciación general, se podría afirmar que mientras el objetivo de los planes de desarrollo desde el 2007 hasta el 2013 era la reducción de la inequidad y la distribución de medios de producción, para el PNBV 2013-2017 el enfoque fue erradicar la pobreza sin mirar las estructuras que la producen, sin cuestionar los modos de acumulación y con una apuesta a los mega proyectos de cambio de matriz energética y a la industria minera (KING, 2014). Con ello se 
verifica que, al igual que en el caso brasilero $o$ argentino, no se modificaron los patrones de distribución ni de consumo y que

en sintonía con las estrategias del Banco Mundial, se abandonó la política de redistribución de la riqueza y en su lugar se profundizan las destinadas a combatir la pobreza. (ZIBECHI, 2006, P. 2).

Cabe acotar que incluso cuando el gasto social importante y la inclusión de grupos vulnerables podría suponer un incremento de poder social fomentando una transición hacia otro modo civilizatorio, es evidente que el carácter asistencial de la política social se orienta hacia la contención de conflictos existentes o potenciales derivados del extractivismo, reforzando la tesis de una adecuada gobernabilidad más que un cambio estructural o de la implementación de otro paradigma (BREILH, 2014; MUÑOZ; CARRIÓN, 2013).

En ese sentido, con un Sumak Kawsay como concreción de varios años de lucha del movimiento indígena, que plantea la defensa de los territorios en el sentido metafísico descrito por Altman y varios teóricos indígenas, vale la pena plantearse las preguntas que proponía Canclini (1983, P. 28) respecto de si las culturas andinas, son aquellas:

supervivencias precapitalistas en proceso de extinguirse, incapaces de actuar cómo agentes transformadores? O podemos considerarlas una alternativa al desarrollo hegemónico, precisamente por el carácter 'disfuncional' de sus hábitos de producción y consumo, de sus creencias impermeables al saber que les imponen.

¿Es el Sumak Kawsay un concepto que debe ser abandonado, toda vez que se ha vaciado de contenido? Insistimos en que no. Desde la salud por ejemplo lo que aporta la concepción de salud/Buen Vivir de la organización indígena campesina y la organización de parteras es una resistencia a la modernidad

como tendencia civilizatoria dotada de un nuevo principio unitario de coherencia o estructuración para la vida social civilizada y para el mundo correspondiente a esa vida (ECHEVERRÍA, 2009, P. 7-8), [una resistencia a la obsolescencia de lo ancestral].

Esta resistencia se fundamenta, como explicaba Echeverría, en la capacidad de acercarse a la naturaleza en términos sagrados y no puramente profanos matematizados. Es esa conexión "que implic(a) determinantemente el recurso de operaciones de orden mágico" (ECHEVERRÍA, 2009, P. 9) con la naturaleza la que posibilita la resistencia y le da sentido a la construcción de otros modos de salud.

Es más, la defensa del Sumak Kawsay como lo construye y lo disputa el movimiento indígena, así como la recuperación de saberes ancestrales, es una resistencia importante a la modernidad. Con la caza de brujas, se perseguía también la magia/espiritualidad/ conexión con la naturaleza. La organización capitalista del trabajo trató de controlar la naturaleza rechazando lo impredecible de la magia y sobre todo, la relación con la naturaleza/ separación sujeto del objeto.

De esta forma, aunque la explotación y expropiación se da en el plano material y es en ese plano que hay que disputar el poder político para transformar y construir el otro mundo posible que soñamos en América Latina; la espiritualidad, la remediación primordial de la herida con la naturaleza, la construcción colectiva de salud, el cuidado de la vida, son formas esenciales -tanto como la formación de sindicatos o la formación política de los movimientos sociales- para la resistencia al capitalismo y la derrota de él en pos de algo común. 


\section{Referências}

ACOSTA, A. Extractivismo y neoextractivismo: dos caras de la misma maldición. In: LANG, M; MOKRANI, D. (Org.). Más allá del desarrollo. Quito: Fundación Rosa Luxemburg; AbyaYala, 2011. p. 83-118.

ALTMAN, P. El Sumak Kawsay en el discurso del movimiento indígena ecuatoriano. Indiana, Berlin, v. 30, p. 283-299, 2013. Disponible en: <http://www.iai.spk-berlin.de/fileadmin/dokumentenbibliothek/Indiana/ Indiana_30/IND_30_2013_283-299_Altmann.pdf>.

Acceso en: 2 abr. 2017

BREILH, J. La Salud en el Neoproductivismo con Gobernanza. In: CONFERENCIA ANUAL ECUADOR, 2014, Quito. Anuales... Quito: [S. n.], 2014. p. 1-22.

CANCLINI, N. G. Gramsci e as Culturas Populares na América Latina. In: COUTINHO, C. N.; NOGUEIRA, M. A. (Org.). Gramsci e a América Latina. São Paulo: Paz e Terra, 1983. p. 61-83.

CHOQUEHUANCA, D. Hacia la reconstrucción del Vivir Bien. América Latina en Movimiento, Quito, n. 452, p. 6-13, feb. 2010.

DÁVALOS, P. Salud Inc.: monopolio, ganancia y asimetrías de la información en el aseguramiento privado de la salud en el Ecuador. Quito: PUCE, 2016. Disponible en: <http://saludyderechos.fundaciondonum.org/ wp-content/uploads/2016/08/Salud-Inc-Medicinaprepagada.pdf>. Acceso en: 2 abr. 2017.

DOMÍNGUEZ, R.; CARIA, S. La ideología del Buen Vivir: la metamorfosis de una alternativa al desarrollo en desarrollo de toda la vida. Universidad Andina Simón Bolívar, Quito, n. 2, p. 1-31, 2014. Disponible en: <http:// repositorio.uasb.edu.ec/bitstream/10644/3724/1/ PRET-002-Dominguez-Car\%C3\%ADa-La\%20 ideolog\%C3\%ADa.pdf >. Acceso en: 2 abr. 2017.

ECHEVERRÍA, B. ¿Qué es la modernidad? México: Universidad Nacional Autónoma de México, 2009.

ECUADOR. Diez Años Después: Salud. El Telégrafo, Equador, 2017. Disponible en: <http://www.eltelegrafo.
com.ec/especiales/2017/Ecuador-antes-y-despues/ salud.html>. Acceso en: 7 abr. 2017.

Plan Nacional de Desarrollo. Plan Nacional para el Buen Vivir 2009-2013. 2. ed. Quito: Secretaría $\mathrm{Na}$-cional de Planificación y Desarrollo, 2009. Disponible en: <http://www.planificacion.gob.ec/wp-content/uploads/downloads/2012/07/Plan_Nacional_ para_el_Buen_Vivir.pdf>. Acceso en: 7 abr. 2017.

Presidencia República del Ecuador. Presidente suscribió decreto que reduce sueldos a autoridades nacionales y altos funcionarios del gobierno. Quito, 24 feb. 2015. Disponible en: <http://www.presidencia.gob.ec/ decreto-601/>. Acceso en: 7 abr. 2017.

HOUTART, F. El concepto de Sumak Kawsay (Buen vivir) y su correspondencia con el bien común de la humanidad (Tema Central). Ecuador Debate, Quito, n. 84 , p. $57-73,2011$.

ITURRALDE, P. El Negocio Invisible de la Salud: Análisis de la Acumulación de Capital en el Sistema de Salud del Ecuador. Quito: CDES, 2014.

KING, K. Perspectiva Económica del Plan Nacional del Buen Vivir 2013- 2017. marzo 2014. Disponible en: <http://www.katiuskaking.com/2014/03/30/ perspectiva-economica-del-plan-nacional-del-buen-vivir-2013-2017/>. Acceso en: 25 jul. 2016. No paginado.

LANG, M.; MOKRANI, D. (Org.). Más allá del desarrollo. Quito: Fundación Rosa Luxemburg; AbyaYala, 2011.

MACAS, L. Sumak Kawsay: la vida en plenitud. América Latina en Movimiento, Quito, n. 452, p 14-16, feb. 2010.

MALDONADO, L. El Sumak Kawsay como Alternativa al Desarrollo. In: SEMINARIO INTERCULTURALIDAD Y SALUD, 2009, Quito. Anuales... Quito: [S. n.], 2009.

MARCIAL, D. Adicción a la 'coca cola' en el México 
indígena. El País, México, 6 oct. 2016. Disponible en: <http://internacional.elpais.com/internacional/2016/10/05/mexico/1475622999_083399.html. Acceso en: 7 oct. 2016. No paginado.

\section{MUÑOZ, F.; CARRIÓN, D. Cambio de Matriz}

Productiva: IlusiónMovilizadora y lucha de posiciones. Lalineadefuego, Quito, 6 oct. 2013. Disponible en: $<$ http://lalineadefuego.info/2013/06/10/cambio-de-matriz-productiva-ilusion-movilizadora-y-lucha-de-posiciones-por-francisco-munoz-jaramillo-y-diego-carrion/\#_ftnref15>. Acceso en: 25 jul. 2016.

\section{NOBOA, H. Inequidades en Mortalidad Materna en}

Ecuador 2015. Disponible en: <https://www.dropbox. com/s/niw79qvrzlil3si/Inequidades\%20en\%20mortalidad\%20materna\%20en\%20el\%20Ecuador.pdf?dl=0>. Acceso en: 7 oct. 2016.

OSPINA, P. Ecuador: el nuevo período de gobierno y el cambio de la matriz productiva. Informe de coyuntura, Quito, p. 1-12, jul. 2013. Disponible en: < https://lalineadefuego.info/2013/07/19/ecuador-el-nuevo-periodo-de-gobierno-y-el-cambio-de-la-matriz-productiva-pablo-ospina-peralta/>. Acceso en: 7 oct. 2016.
RUIZ, A. M. Eco-socialismo: discurso crítico de la Revolución. Rebelión, Quito, p. 1-7, enero 2013. Disponible en: <http://www.rebelion.org/docs/163084. pdf $>$. Acceso en: 7 abr. 2017.

SIMBAÑA, F. El Sumak Kawsay como proyecto político. In: LANG, M.; MOKRANI, D. (Org.). Más allá del desarrollo. Quito: Fundación Rosa Luxemburg; AbyaYala, p. 83-118, 2011.

VILLAVICENCIO, A. Ecuador: El Cambio de Matriz Productiva o la mayor estafa política de la historia. Sinpermiso, [S. 1.], sept. 2016. Disponible en: <http:// www.sinpermiso.info/textos/ecuador-el-cambio-de-la-matriz-productiva-o-la-mayor-estafa-politica-de-la-historia>. Acceso en: 7 oct. 2016. No paginado.

ZIBECHI, R. América Latina: la Nueva Gobernabilidad. América Latina en Movimiento Online, Quito, jun.

2006. Disponible en: <http://www.alainet.org/es/active/11980>. Acceso en: 7 oct. 2016.

Recibido para publicación en abril de 2017

Versión final en junio de 2017

Conflicto de intereses: inexistente

Apoyo financiero: inexistente 